\title{
Uso da tomografia computadorizada no diagnóstico do COVID-19
}

\section{Use of computerized tomography in the diagnosis of COVID-19}

Uso de la tomografía computarizada en el diagnóstico de COVID-19

Lucas Caetano Castelo Branco ORCID: https://orcid.org/0000-0003-4227-2533 Instituto Federal do Piauí, Brasil E-mail: lucascastelobranco@live.com Lucas Costa de Gois ORCID: https://orcid.org/0000-0002-2569-5553 Universidade Estadual do Piauí, Brasil E-mail: goislucas2013@outlook.com

Sabrina Brenda Castelo Branco Silva ORCID: https://orcid.org/0000-0002-2807-9043 Universidade Estadual do Piauí, Brasil

E-mail: sabrinabrenda.2006@hotmail.com

Giesley Queiroz Teixeira Castelo Branco ORCID: https://orcid.org/0000-0002-0211-5296 Centro Universitário Uniasselvi, Brasil E-mail: giesley@hotmail.com Yara de Sousa Oliveira

ORCID: https://orcid.org/0000-0001-7095-6153 Universidade Estadual do Piauí, Brasil

E-mail: yarasousa.oliveira88@gmail.com Karllenh Ribeiro dos Santos

ORCID: https://orcid.org/0000-0002-5035-366X Universidade Estadual do Piauí, Brasil

E-mail: ribeirokarllenh@gmail.com

Natanael Nunes da Silva

ORCID: https://orcid.org/0000-0002-5419-2090 Universidade Estadual do Piauí, Brasil

E-mail: natanaellp2@ hotmail.com

Sebastião Bezerra da Silva Neto ORCID: https://orcid.org/0000-0002-3259-8380 Hospital Universitário do Piaú, Brasil E-mail: sebastiangelus@gmail.com

Bruno Abílio da Silva Machado ORCID: https://orcid.org/0000-0003-1759-0206 Centro Universitário Maurício de Nassau, Brasil E-mail: bruno.smachado@ufpe.br

Mariana Pereira Barbosa Silva ORCID: https://orcid.org/0000-0003-0852-8099 Universidade Estadual do Piauí, Brasil E-mail: marianapbsilvaa@gmail.com

Samuel Lopes dos Santos

ORCID: https://orcid.org/0000-0003-3375-9171 Universidade Federal do Piauí, Brasil

E-mail: samuellopes121314@gmail.com

Herculys Douglas Clímaco Marques ORCID: https://orcid.org/0000-0002-5106-6187 Instituto Federal do Piauí, Brasil E-mail: herculysdouglas@gmail.com

Ronald Gerard Silva

ORCID: https://orcid.org/0000-0003-4645-0798 Hospital Universitário do Piauí, Brasil

E-mail: ronaldsgerard@yahoo.com.br

Idna de Carvalho Barros Taumaturgo ORCID: https://orcid.org/0000-0001-8293-543X Instituto Federal do Piauí, Brasil E-mail: idnabarros@gmail.com

Jâmeson Ferreira da Silva

ORCID: https://orcid.org/0000-0003-1977-3460 Instituto Federal do Piauí, Brasil E-mail: jameson@ifpi.edu.br 


\begin{abstract}
Resumo
Objetivo: Fornecer uma avaliação atualizada do uso da Tomografia Computadorizada nos casos de COVID-19. Metodologia: Esta pesquisa pertence a um estudo de revisão integrativa da literatura operacionalizada, tendo como norte as seguintes fases: reconhecimento da temática e a distinção da interrogação da pesquisa; organização dos critérios de exclusão e inclusão; consolidação dos estudos escolhidos; distribuição dos trabalhos eleitos; observação das pesquisas e esclarecimento dos resultados; por fim, a exibição da revisão compreendida. Resultados: Desse modo, os estudos foram publicados com predominância no ano de 2020 sendo o equivalente de $75 \%$ de todos os artigos usados para o estudo e cerca de $25 \%$ no ano de 2021. Diante disso, a maioria dos trabalhos eram dos Estados Unidos 25\%, contra 12,5\% da França, 12,5\% da Holanda, 12,5\% da Alemanha, 12,5\% Indonésia, 12,5\% da Holanda e 12,5\% da Espanha. Sendo assim, os principais achados em pacientes com suspeita de COVID-19 foram em primeiro lugar: Opacidade em vidro fosco, em segundo lugar: Consolidações, em terceiro lugar: padrão reticular, septo interlobular engrossado, broncograma aéreo e bronquiolectasia. Dessa forma, os padrões predominantes caracterizaram uma certa prevalência nos pacientes que compareceram para a realização da Tomografia Computadorizada. Conclusão: Concluise que o uso da Tomografia Computadorizada para o diagnóstico do Covid-19 é de extrema valia, pois o mesmo apresenta diversos pontos favoráveis para a sua continuação, sendo eles, para o acompanhamento clínico, evolução dos pacientes, estabelecimento de sucesso em drogas de escolha clínica e até mesmo para o diagnóstico de casos não identificados no teste RT-PCR.
\end{abstract}

Palavras-chave: Tomografia computadorizada por raios X; Infecção por vírus COVID 19; COVID-19.

\begin{abstract}
Objective: To provide an up-to-date assessment of the use of CT in cases of COVID-19. Methodology: This research belongs to an integrative review of operationalized literature, guided by the following phases: recognition of the dimension and precision of the interrogation of the literature; the exclusion and inclusion criteria; development of the chosen studies; distribution of elected works; observation of the research and clarification of the results; finally, the display of the complete review. Results: Thus, the studies were predominantly published in the year 2020, being equivalent to $75 \%$ of all articles used for the study and about $25 \%$ in the year 2021 . Therefore, most of the works were from the United States 25\%, against $12.5 \%$ for France, $12.5 \%$ for the Netherlands, $12.5 \%$ for Germany, $12.5 \%$ for Indonesia, $12.5 \%$ for the Netherlands and $12.5 \%$ for Spain. Therefore, the main findings in patients with suspected COVID-19 were found at the site: first, ground-glass opacity, second: Consolidations, third: reticular pattern, thickened interlobular septum, air bronchogram, and bronchiolectasis. Thus, the patterns characterize a certain prevalence in patients who present for CT. Conclusion: Conclusion- It is concluded that the diagnosis of Covid-19 is of extreme evaluation of patients, as it has several evolution computers for clinical follow-up, of patients, establishment of success for clinical follow-up, of patients, establishment of evolution for clinical follow-up of patients, establishment of drugs of clinical choice, even for the diagnosis of cases not identified in the RT-PCR test.

Keywords: X-ray computed tomography; COVID 19 virus infection; COVID-19.
\end{abstract}

\title{
Resumen
}

Objetivo: Proporcionar una evaluación actualizada del uso de la TC en los casos de COVID-19. Metodología: Esta investigación pertenece a una revisión integradora de la literatura operacionalizada, guiada por las siguientes fases: reconocimiento de la dimensión y precisión de la interrogación de la literatura; criterios de exclusión e inclusión; desarrollo de los estudios elegidos; distribución de obras seleccionadas; observación de la investigación y aclaración de los resultados; finalmente, la visualización de la revisión completa. Resultados: Así, los estudios fueron publicados predominantemente en el año 2020, siendo equivalente al $75 \%$ de todos los artículos utilizados para el estudio y cerca del $25 \%$ en el año 2021. Por lo tanto, la mayoría de los trabajos fueron de los Estados Unidos. 25\%, contra 12,5\% de Francia, $12,5 \%$ de Holanda, 12,5\% de Alemania, $12,5 \%$ de Indonesia, 12,5\% de Holanda y 12,5\% de España. Por lo tanto, los principales hallazgos en pacientes con sospecha de COVID-19 se encontraron en el sitio: primero, opacidad en vidrio esmerilado, segundo: Consolidaciones, tercero: patrón reticular, tabique interlobulillar engrosado, broncograma aéreo y bronquiolectasias. Así, los patrones caracterizan una cierta prevalencia en los pacientes que acuden a TC. Conclusión: Conclusión- Se concluye que el diagnóstico de Covid-19 es de extrema evaluación de pacientes, ya que cuenta con varios computadores de evolución para seguimiento clínico, de pacientes, establecimiento de éxito para seguimiento clínico, de pacientes, establecimiento de evolución para el seguimiento de los pacientes, establecimiento de fármacos de elección clínica, incluso para el diagnóstico de casos no identificados en la prueba RT-PCR.

Palabras clave: Tomografía computarizada de rayos X; Infección por el virus COVID 19; COVID-19.

\section{Introdução}

A COVID-19, é uma enfermidade altamente infecciosa causada pela síndrome respiratória aguda grave coronavírus 2

(SARS-CoV-2). Dessa forma, teve seu relato visto pela primeira vez na cidade de Wuhan, que fica na província de Hubei, na

China. Diante disso, aceleradamente se espalhou para outras regiões da China e para outros países. Desse modo, na data de 30 
de janeiro de 2020, a Organização Mundial da Saúde (OMS) informou para o mundo este surto como uma emergência de saúde pública global, sendo que no dia 28 de fevereiro de 2020 aumentou o risco de COVID-19 para muito alto em nível global (Na et al., \& Tan, 2020; Organização Mundial de Saúde, 2020).

Desse modo, em 2 de março de 2020, um total de 88.948 casos de COVID-19 com 3.043 mortes foram ratificados, sendo que, dos quais 8.774 eram de outros 64 países e 80.174 eram provenientes da China. Diante disso, o padrão de referência para o diagnóstico de COVID-19 é a reação em cadeia da polimerase de transcrição reversa em tempo real (RT-PCR). Porém, algumas pesquisas mostraram que a Tomografia Computadorizada possui como sensibilidade o diagnóstico em 98\% nos pacientes cujo o exame de RT-PCR derem falsos-negativos (Organização Mundial de Saúde, 2020; Xie et al., 2020; Huang et al., 2020; Fang et al., 2020).

Nessa perspectiva, vale salientar que a Tomografia Computadorizada foi definida como de grande importância não só para o diagnóstico, mas também para o monitoramento dos estágios da doença e para a avaliação da eficácia terapêutica utilizada no paciente. sendo isso, declarado pela Comissão Nacional de Saúde da República Popular da China (CNSRPC) em seu protocolo oficial de diagnóstico e tratamento (Comissão Nacional de Saúde da República Popular da China, 2020).

Dessa maneira, a marca registrada da COVID-19 é a distribuição bilateral de Opacidades em Vidro Fosco (OVF) com a presença ou não de consolidações nos pulmões. Dessa forma, após uma observação mais completa dos crescentes casos de COVID-19, notou-se que existe variedades de características na imagem de Tomografia Computadorizada visíveis, contendo alterações das vias aéreas, sinal do halo invertido e o padrão de pavimentação em mosaico dentre outras (Wang et al., 2020; Michael et al., 2020.; Yiecheng et al., 2020; Bernheim et al., 2020).

Desse modo, pode-se inferir que uma abordagem integrada de tomografia computadorizada pode proporcionar informações de grande valor sobre o diagnóstico, acompanhamento e prognóstico de pacientes com a infecção do novo coronavírus. Sendo assim, este estudo teve como objetivo fornecer uma avaliação atualizada do uso da Tomografia Computadorizada nos casos de COVID-19.

\section{Metodologia}

Esta pesquisa pertence a um estudo de revisão integrativa da literatura operacionalizada, tendo como norte as seguintes fases: reconhecimento da temática e a distinção da interrogação da pesquisa; organização dos critérios de exclusão e inclusão; consolidação dos estudos escolhidos; distribuição dos trabalhos eleitos; observação das pesquisas e esclarecimento dos resultados; por fim, a exibição da revisão compreendida (Mendes et al., 2008).

O estudo em questão tem como tema escolhido o Uso da Tomografia Computadorizada no Diagnóstico do COVID19. A tomografia computadorizada é diretamente ligada a eficiência do diagnóstico clinico da COVID-19, pois até mesmo nos casos em que o exame de Reação da Transcriptase Reversa-Reação em Cadeia da Polimerase (RT-PCR) der negativo mas que a clínica seja evidentemente clara para o diagnóstico, a Tomografia Computadorizada entra sendo a divisora entre a dúvida e a certeza.

Foi realizado um estudo de revisão integrativa da literatura, tendo como base periódicos publicados nas bases de dados PUBMED, SCIELO e na Biblioteca Virtual de Saúde (BVS). Os critérios de inclusão foram, estudos dentro do período de 2016 a 2021, nos idiomas português, inglês e espanhol, na íntegra, a partir da combinação dos seguintes descritores: Tomografia Computadorizada por Raios X, Infecção por vírus COVID 19 e COVID-19. Diante disso, já os critérios de exclusão foram todos os artigos que não observaram a questão norteadora deste estudo e que não se estabeleceram dentro dos critérios de inclusão.

Dessa forma, a pesquisa agregou 18 estudos selecionados para uma averiguação minuciosa, dos quais 10 se estabeleceram dentro dos critérios de inclusão. Sendo assim, os dados obtidos foram apresentados em tabelas, analisados e 
interpretados conforme os objetivos do presente trabalho tendo como norte para os próximos passos a literatura preconizada inicialmente.

\section{Resultados e Discussão}

Nessa perspectiva, abaixo apresentam-se os resultados dessa pesquisa, dividido em duas tabelas, sendo a Tabela 1, de caracterização dos artigos, e a Tabela 2, de análise do exposto em cada um dos artigos. Dessa forma, a Tabela 01 apresenta 2 artigos publicados na Revista Einstein, 1 artigo publicado na Revista European Radiology, 1 na Revista Radiology, 1 no Sage Journals, 1 na Acta Med Indones J Intern Med, 1 na Emerging Microbes e Infections, 1 na Med Clin Barcelona, 1 na European Journal of Nuclear and Molecular Imaging e por fim 1 no Journal of Cardiovascular Computed Tomography.

Desse modo, os estudos foram publicados com predominância no ano de 2020 sendo o equivalente de $70 \%$ de todos os artigos usados para o estudo e cerca de $30 \%$ no ano de 2021. Diante disso, a maioria dos trabalhos eram dos Estados Unidos $20 \%$ e do Brasil 20\%, contra 10\% da França, 10\% Inglaterra, 10\% da Holanda, 10\% da Alemanha, 10\% Indonésia e 10\% da Espanha. Dessa maneira, os conteúdos das pesquisas encontradas referiam-se sobre o uso da Tomografia Computadorizada na abordagem frente aos pacientes com a infecção do COVID-19 (Table 2).

\section{Achados diagnósticos de COVID-19 na Tomografia Computadorizada}

Sendo assim, os principais achados em pacientes com suspeita de COVID-19 foram em primeiro lugar: Opacidade em vidro fosco, em segundo lugar: Consolidações, em terceiro lugar: padrão reticular, septo interlobular engrossado, broncograma aéreo e bronquiolectasia. Dessa forma, os padrões predominantes caracterizaram uma certa prevalência nos pacientes que compareceram para a realização da Tomografia Computadorizada (Ye et al., 2020).

Desse modo, evidenciou-se que além do indício da opacidade em vidro fosco, alguns pacientes também apresentavam pavimentação em mosaico, sendo mais uma característica sugestiva para o diagnóstico em pacientes com sinais clínicos da COVID-19. Dessa maneira, vale a pena salientar que em alguns casos na angiotomografia das artérias pulmonares pode-se notar uma falha em seu enchimento, caracterizando um grande risco de embolia pulmonar. Diante disso, nota-se que a COVID19 pode apresentar padrões diferentes em decorrência das características individuas de cada pessoa (Pontone et al., 2021). 
Research, Society and Development, v. 11, n. 3, e43611326764, 2022

(CC BY 4.0) | ISSN 2525-3409 | DOI: http://dx.doi.org/10.33448/rsd-v11i3.26764

Tabela 1: Caracterização dos artigos. Teresina - PI 2022 (N=08).

\begin{tabular}{|c|c|c|c|c|c|c|}
\hline $\mathrm{N}^{\circ}$ & Título & Autoria & Base & Ano & País & Revista \\
\hline 1 & $\begin{array}{l}\text { Manifestações de TC de tórax da nova doença coronavírus } 2019 \\
\text { (COVID-19): uma revisão pictórica }\end{array}$ & Ye, et al. & PUBMED & 2020 & França & European Radiology \\
\hline 2 & Papel da tomografia computadorizada no COVID-19 & Pontone, et al. & PUBMED & 2021 & Holanda & Journal of cardiovascular computed tomography \\
\hline 3 & $\begin{array}{l}\text { Imagem e características clínicas de pacientes com o novo } \\
\text { coronavírus SARS-CoV-2 }\end{array}$ & $\mathrm{Xu}$, et al. & PUBMED & 2020 & Alemanha & European Journal of Nuclear and Molecular Imaging \\
\hline 4 & $\begin{array}{l}\text { Tomografia Computadorizada para Pneumonia Típica 2019-nCoV: } \\
\text { Relação com Teste Negativo de RT-PCR }\end{array}$ & Xie, et al. & PUBMED & 2020 & $\begin{array}{l}\text { Estados } \\
\text { Unidos }\end{array}$ & Radiology \\
\hline 5 & $\begin{array}{l}\text { Eficácia de corticosteroides no peito tomografia computadorizada de } \\
\text { alta resolução características de pneumonia COVID-19 }\end{array}$ & Calabrese, et al. & PUBMED & 2021 & $\begin{array}{l}\text { Estados } \\
\text { Unidos }\end{array}$ & Sage Journals \\
\hline 6 & $\begin{array}{l}\text { A Importância da Tomografia Computadorizada no COVID-19: } \\
\text { uma série de casos }\end{array}$ & Tenda, et al. & BVS & 2020 & Indonésia & $\begin{array}{l}\text { Acta Med Indones } \\
\mathrm{J} \text { Intern Med }\end{array}$ \\
\hline 7 & $\begin{array}{l}\text { Valor diagnóstico e principais características da tomografia } \\
\text { computadorizada na nova doença do Coronavírus } 2019\end{array}$ & $\mathrm{Li}$, et al. & BVS & 2020 & Inglaterra & Emerging Microbes e Infections \\
\hline 8 & $\begin{array}{l}\text { Radiologia no diagnóstico de pneumonia SARS-CoV-2 (COVID- } \\
\text { 19) }\end{array}$ & Sanchez, et al. & PUBMED & 2020 & Espanha & Med Clin Barcelona \\
\hline 9 & $\begin{array}{l}\text { Tomografia Computadorizada de Tórax no diagnóstico de COVID- } \\
19 \text { em pacientes com resultado falso-negativo na RT-PCR }\end{array}$ & Fonseca, et al. & SCIELO & 2021 & Brasil & Einstein \\
\hline 10 & $\begin{array}{lcccc}\text { Achados da } & \text { COVID-19 } & \text { identificados } & \text { na } & \text { Tomografia } \\
\text { Computadorizada de Tórax: ensaio pictórico } & & \\
\end{array}$ & Rosa, et al. & SCIELO & 2020 & Brasil & Einstein \\
\hline
\end{tabular}

Fonte: Autores (2022). 
Tabela 2: Análise de conteúdo dos artigos. Teresina - PI 2022 (N=08).

\begin{tabular}{|l|l|}
\hline $\mathrm{N}^{\circ}$ & OBJETIVOS \\
\hline 1 & $\begin{array}{l}\text { Resumir as típicas e relativamente atípicas manifestações de COVID-19 em } \\
\text { tomografia de tórax de forma pictórica e ajudar os radiologistas a familiarizar esses } \\
\text { possíveis recursos de imagem de COVID-19. }\end{array}$ \\
\hline 2 & $\begin{array}{l}\text { Apresentar uma análise de aplicações avançadas de tomografia cardíaca para precoce } \\
\text { estratificação de risco de formas graves da doença. }\end{array}$ \\
\hline 3 & $\begin{array}{l}\text { O objetivo é descrever características clínicas e de imagem de tomografia } \\
\text { computadorizada de 90 pacientes com infecção por SARS-CoV-2 e aparições de } \\
\text { acompanhamento precoce de 52 pacientes. }\end{array}$ \\
\hline 4 & $\begin{array}{l}\text { Descrever características de imagem tomográficas de cinco pacientes com inicial } \\
\text { resultados negativos ou fracamente positivos do RT-PCR, mas alta suspeita de } \\
\text { infecção por 2019-nCov. }\end{array}$ \\
\hline 5 & $\begin{array}{l}\text { Avaliar o efeito de um tratamento de curto prazo com doses de corticosteroide de } \\
\text { baixa termederato (SC) por uma avaliação quantitativa e qualitativa do tórax HRCT } \\
\text { de pneumonia COVID-19. }\end{array}$ \\
\hline 6 & $\begin{array}{l}\text { Investigar a importância e utilidade de tomografia computadorizada torácica (TC) no } \\
\text { diagnóstico de COVID-19, como aumento de evidências sugerindo que tomografia } \\
\text { do peito pode ser útil na via clínica no diagnóstico de COVID-19. }\end{array}$ \\
\hline 7 & $\begin{array}{l}\text { Esta revisão foca nas características de imagem e mudanças ao longo do curso da } \\
\text { doença em pacientes com COVID-19, e uma comparação entre o COVID-19 e } \\
\text { outras doenças que possuem achados semelhantes da Tomografia Computadorizada. }\end{array}$ \\
\hline 8 & $\begin{array}{l}\text { Identificar as características desta pneumonia viral rapidamente progressiva em } \\
\text { exames de imagem, tanto no TRT quanto no TCT. }\end{array}$ \\
\hline 9 & $\begin{array}{l}\text { Avaliar o papel da tomografia computadorizada de tórax em pacientes com COVID- } \\
19 \text { que apresentaram reação em cadeia da polimerase via transcriptase reversa (RT- } \\
\text { PCR) inicial falsamente negativa }\end{array}$ \\
\hline 10 & $\begin{array}{l}\text { Identificar achados da COVID-19 que são identificados na tomografia } \\
\text { computadorizada de tórax }\end{array}$ \\
\hline
\end{tabular}

\section{CONCLUSÃO}

O reconhecimento precoce e o isolamento dos pacientes COVID-19 são de importância crucial no controle desse surto, especialmente naqueles com falso RT-PCR negativo ou sem sintomas.

Durante a pandemia SARS-Cov-2, a tomografia computadorizada pode ser usada como abrangente modalidade de imagem não invasiva que permite a avaliação do parênquima pulmonar, patência de artérias pulmonares e coronárias e danos do miocárdio.

Várias opacidades de vidro moído irregulares em lobular múltiplo bilateral com distribuição de periferia são peito típico na imagem da pneumonia COVID-19.

No contexto de apresentação clínica típica e exposição a outros indivíduos com 2019-nCoV, características de TC de pneumonia viral pode ser fortemente suspeita para a infecção por 2019-nCoV apesar de RT-PCR negativa.

A melhoria de todos os achados de HRCT torácico apoia ainda mais o papel da CS terapia adjuntiva em pneumonia COVID-19 grave/crítica.

Sugere-se o uso de tomografia torácica sem contraste para diagnosticar COVID-19 em pacientes que mostram moderada sintomas com quaisquer achados vagos do peito em uma radiografia apesar de um resultado negativo para RT-PCR.

A aparência e exacerbação dos sinais de consolidação pulmonar podem estar relacionadas à progressão da doença e o valor diagnóstico do prognóstico dos pacientes.

No caso de pacientes com resultados negativos da RC, mas com manifestações clínicas típicas, histórico de exposição e, portanto, alta suspeita clínica de infecção, TCT pode ser uma técnica de diagnóstico de alto valor, porque pode demonstrar os achados característicos da doença.

A tomografia computadorizada pode ter papel importante no manejo de casos suspeitos de COVID-19, que apresentaram resultado negativo inicial na reação em cadeia da polimerase via transcriptase reversa, principalmente levando em consideração os pacientes que estão fora da janela ideal de coleta de amostras. Somente um paciente teve resultado negativo na tomografia computadorizada inicial, de acordo com a classificação do Consenso da Radiological Society of North America, e o software demonstrou probabilidade de COVID-19 >25\% na maioria dos pacientes que apresentaram resultado inicial negativo na reação em cadeia da polimerase via transcriptase reversa, mas tiveram diagnóstico final de COVID-19 Embora o diagnóstico de COVID-19 só possa ser confirmado por meio da reação em cadeia polimerase, a tomografia computadorizada pode auxiliar na avaliação da extensão da doença, das possíveis complicações e na determinação de diagnósticos alternativos. Para tanto, é importante que a equipe envolvida no atendimento conheça os achados sugestivos de pneumonia viral compatíveis com COVID-19.

Fonte: Autores (2022). 
Em um estudo efetivado numa cidade da China onde foram submetidos pacientes para a realização de uma Tomografia de Tórax sem contraste, determinaram como padrão: Kv: 120, mA: 210, espessura mínima de corte: $1 \mathrm{~mm}$ e avaliação por dois Radiologistas com tempo de experiência na prática de laudos em exames de imagem de 15-20 anos demonstrou que de 90 pacientes avaliados 69 apresentavam anormalidades, sendo que, 53 deles estavam com no mínimo dois lobos do pulmão afetados. Dessa forma, mais da metade dos pacientes apresentavam lesões pulmonares multifocais bilaterais com distribuição periférica (Xu et al., 2020).

Nessa perspectiva, em outro estudo, que foi realizado na província de Huan onde pacientes com COVID-19 foram confirmados com testes laboratoriais, dos 167 pacientes confirmados, a pesquisa trabalhou com os dados de 5 , onde obtiveram a ajuda de 2 Radiologistas com 10 anos de experiência para a análise das imagens desses indivíduos, logo, foi constatado o mesmo que outros autores já citados obtiveram: Opacidades em vidro fosco, consolidações envolvendo regiões subpleurais e consolidações mistas com opacidades em vidro fosco (Xie, et al., 2020).

Diante disso, vale salientar que outro estudo realizado em 2020 na Indonésia, caracterizou o caso de um paciente de 52 anos, hipertenso, com histórico de 5 dias seguidos de febre que piorava durante a tarde ou pela noite e com presença de diarreia desde o início dos sintomas febris, ausência de tosse, expectoração e dispneia foi relatada pelo cidadão, após a checagem clínica ele foi submetido a uma Tomografia Computadorizada de Tórax sem contraste, logo, foi observado mais uma vez o que os demais autores já revelaram, sendo os principais achados: Opacidade em vidro fosco periférico, espessamento do septo interlobular em quase todo segmento de ambos os pulmões com sugestão de pneumonia intersticial viral (Tenda et al., 2020).

\section{Vantagens e desvantagens do uso da Tomografia Computadorizada}

Sendo assim, pode-se inferir que durante a pandemia do COVID-19, a Tomografia Computadorizada de tórax sem contraste possui como vantagem por ser um método não invasivo que permite uma abrangente avaliação do pulmão, do coração e da permeabilidade das artérias coronarianas e pulmonares. Dessa forma a Tomografia mostra-se ser uma técnica de imagem com bons resultados para o diagnóstico, até mesmo de pacientes assintomáticos (Pontone, et al., 2021; Sanchez et al., 2020).

Dessa maneira, em uma conclusão de uma pesquisa endereçada numa revista internacional, evidenciou que embora a Tomografia Computadorizada de Tórax seja extremamente valiosa para uma melhor abordagem clínica do paciente ela não é considerada padrão ouro, pois a mesma não é capaz de discernir o microrganismo responsável pela infecção e isso caracteriza uma das desvantagem da mesma para a investigação da patologia, logo, o exame RT-PCR continua sendo o prioritário para o correto diagnóstico da COVID-19 pelo fato da identificação especifica do vírus (Lia et al., 2020).

Nessa perspectiva, o diagnóstico de COVID-19 só pode ser confirmado por meio da reação em cadeia de polimerase. Diante disso, pode-se inferir que a Tomografia Computadorizada é vista como um método auxiliar, permitindo uma avaliação da extensão do vírus, na determinação de diagnósticos alternativos e no acompanhamento das possíveis complicações. Em vista disso, vale a pena salientar que é de extrema importância que a equipe que participa do processo frente ao diagnóstico da patologia conheça os achados sugestivos de pneumonia viral compatíveis (Rosa et al., 2020).

Dessa forma, nota-se que a Tomografia Computadorizada de tórax é capaz de detectar lesões pulmonares em seu estágio inicial, proporcionando um diagnóstico precoce. Diante disso, vale exemplificar que as características de um paciente com contato prévio com uma pessoa infectada, mostrado após a realização do exame de imagem com opacidades multifocais bilaterais periféricas em vidro fosco, pode ser um sinal bem definidor para que o médico na clínica, durante sua consulta seja capaz de diagnosticar rapidamente (Xu, et al., 2020). 
Desse modo, 167 pacientes foram avaliados e confirmados positivos para a COVID-19, onde 5 deles obtiveram o teste de RT-PCR incialmente negativo e após a realização da Tomografia Computadorizada foram vistos sinais clássicos da infecção. Ao ter tido os sinais sugestivos de pneumonia viral na Tomografia Computadorizada os pacientes entraram em isolamento imediatamente, e após 7 dias, repetiram os testes e só então positivaram para a doença. Dessa forma, isso reforça mais uma vez a importância da tomografia Computadorizada para o diagnóstico da patologia em questão (Xie, et al., 2020).

Sendo assim, a Tomografia Computadorizada pode ter um papel relevante no manejo casos suspeitos de COVID-19, que tiverem inicialmente o desfecho negativo na reação em cadeia de polimerase via transcriptase reversa, especialmente considerando os clientes que estão fora do período padrão para a obtenção de amostras (Fonseca et al., 2021).

Outra abordagem no qual a Tomografia Computadorizada mostrou-se eficaz foi na validação de medicações através da comparação das imagens antes e após a abordagem farmacológica, uma pesquisa quantitativa utilizou uma terapia com corticoides para o tratamento de pacientes graves. Diante disso, eles utilizaram imagens da Tomografia Computadorizada para comprovar a redução das lesões após o início da abordagem medicamentosa, efetivando e consolidando a eficácia do fármaco (Calabrese et al., 2021).

Assim sendo, vale a pena destacar que a partir de um estudo de caso, o pesquisador salientou fortemente a recomendação do uso da Tomografia Computadorizada de tórax sem contraste para diagnosticar a COVID-19 em pacientes que apresentasse sintomas moderados com quaisquer achados na radiografia de tórax e RT-PCR negativo, pois, ela poderá caracterizar um diagnóstico diferencial para esses casos sugestivos que tornaram-se inconclusivos decorrentes dos demais testes (Tenda, et al., 2020).

\section{Conclusão}

Logo, os achados diagnósticos da COVID-19 foram encontrados com uma extrema facilidade nos pacientes positivos, independentemente de os mesmos obtiverem os exames moleculares positivos ou não. Dessa forma, a maioria dos estudos apresentaram as características em sua priori sendo as mais determinantes: Opacidade em vidro fosco, consolidações mistas periféricas e o engrossamento dos septos interlobulares.

Conclui-se então que o uso da Tomografia Computadorizada para o diagnóstico do Covid-19 é de extrema valia, pois o mesmo apresenta diversos pontos favoráveis para a sua continuação, sendo eles, para o acompanhamento clínico, evolução dos pacientes, estabelecimento de sucesso em drogas de escolha clínica e até mesmo para o diagnóstico de casos não identificados no teste RT-PCR.

Para estudos futuros sugere-se que sejam reunidas as possíveis contraindicações do uso da Tomografia Computadorizada nos pacientes com COVID-19, pois as pesquisas em sua maioria falam apenas dos benefícios, não alertando em contrapartida possíveis malefícios do uso dessa prática para o auxílio do diagnóstico do novo Coronavírus Humano.

\section{Referências}

Bernheim, A, Mei, X., Huang, M., Yang, Y., Fayad, Z. A., Zhang, N., Diao, K., Lin, B., Zhu, X., Li, K., Li, S., Shan, H., Jacobi, A. \& Chung, M. (2020). Achados da TC de tórax na doença por coronavírus-19 (COVID-19): relação com a duração da infecção. Radiology, 295(1), 685691. https://pubs.rsna.org/doi/full/10.1148/radiol.2020200463\#: :text=The\%20mean\%20number\%20of\%20days,range\%201\%20\%E2\%80\%93\%2012\%20day

Calabrese, C., Pafundi, P. C., Mollica, M., Annunziata, A., Imitazione, P., Lanza, M., Polistina, G., Flora, M., Guarino, S., Palumbo, C. \& Fiorentino, G. (2021). Eficácia dos corticosteroides em tomografia computadorizada de tórax de alta resolução características da pneumonia COVID-19. Therapeutic Advances in Respiratory Disease, 15, 1-10. https://journals.sagepub.com/doi/full/10.1177/17534666211042533.

Chung, M., Bernheim, A., Mei, X., Zhang, N., Huang, M., Zeng, X., Cui, J., Xu, W., Yang, Y., Fayad, Z. A., Jacobi, A., Li, K., Li, S. \& Shan, H. (2020). Recursos de imagens de TC do novo coronavírus de 2019 (2019-nCoV). Radiology, 295(1), 202-207. https://pubs.rsna.org/doi/full/10.1148/radiol.2020200230.

Comissão Nacional De Saúde Da República Popular Da China. (2020). O protocolo de diagnóstico e tratamento de COVID-19. http://www.gov.cn/zhengce/zhengceku/2020-02/19/content_5480948.htm. 
Fang, Y., Zhang, H., Xu, Y., Xie, J., Pang, P. \& Ji, W. (2020). Manifestações por TC de dois casos de pneumonia pelo novo coronavírus 2019 (2019nCoV). Radiology, 295(1), 208-209. https://pubmed.ncbi.nlm.nih.gov/32031481/.

Fang, Y., Zhang, H., Xie, J., Lin, M., Ying, L., Pang, P. \& Ji, W. (2020). Sensibilidade de TC de tórax para COVID-19: comparação com RT-PCR. Radiology, 296(2), E115-E117. https://pubs.rsna.org/doi/full/10.1148/radiol.2020200432\#: :text=Figure\%203d\%3A-,Discussion,001).

Fonseca, E. K. U. N., Ferreira, L. C., Loureiro, B. M., Strabelli, D. G., Farias, L. P. G., Queiroz, G. A., Garcia, J. V. R., Teixeira, R. F., Gama, V. A. A., Chate, R. C., Júnior, A. N. A., Sawamura, M. V. Y. \& Nomura, C. H. (2021). Tomografia computadorizada de tórax no diagnóstico de COVID-19 em pacientes com resultado falso-negativo na RT-PCR. Einstein. https://www.scielo.br/j/eins/a/6JZ6dKmBLJ6prwkdSNjxQSx/?format=pdf\&lang=pt.

Huang, P., Liu, T., Huang, L., Liu, H., Lei, M., Xu, W., Hu, X., Chen, J. \& Liu, B. (2020). Uso de TC de tórax em combinação com ensaio de RT-PCR negativo para o novo coronavírus de 2019, mas com alta suspeita clínica. Radiology, 295(1), 22-23. https://pubs.rsna.org/doi/full/10.1148/radiol.2020200330.

Lia, B., Lia, X., Wang, Y., Han, Y., Wang, Y., Wang, C., Zhang, G., Jin, J., Jia, H., Fan, F., Ma, W., Liu, H. \& Zhou, Y. (2020). Valor diagnóstico e principais características da tomografia computadorizada na Doença Coronavirus 2019. Emerging Microbes \& Infections, 9(1), 787-793. https://www.tandfonline.com/doi/full/10.1080/22221751.2020.1750307.

Mendes, K. D. S.; Silveira, R. C. C. P. \& Galvão, C. M. (2008). Revisão integrativa: método de pesquisa para a incorporação de evidências na saúde e na enfermagem. Texto Contexto Enfermagem, 17(4), 758-764. https://www.scielo.br/j/tce/a/XzFkq6tjWs4wHNqNjKJLkXQ/abstract/?lang=pt.

Organização Mundial De Saúde. Relatório de situação da doença por coronavírus 2019 (COVID-19) da Organização Mundial da Saúde (2020) - 39. (2020). https://www.who.int/docs/default-source/coronaviruse/situation-reports/20200228-sitrep-39-covid-19.pdf?sfvrsn=5bbf3e7d_2.

Organização Mundial De Saúde. Relatório de situação da doença por coronavírus 2019 (COVID-19) da Organização Mundial da Saúde (2020) - 42. (2020). https://www.who.int/docs/default-source/coronaviruse/situation-reports/20200302-sitrep-42-covid-19.pdf.

Pontone, G., Scafuri, S., Mancini, M. E., Agalbato, C., Guglielmo, M., Baggiano, A., Muscogiuri, G., Fusini, L., Andreini, D., Mushtaq, S., Conte, E., Annoni, A., Formenti, A., Gennari, A. G., Guaricci, A. I., Rabbat, M. R., Pompilio, G., Pepi, M. \& Rossi, A. (2020). Papel da tomografia computadorizada no COVID19. Journal of Cardiovascular Computed Tomography, 15(2021), 27-36. https://www.ncbi.nlm.nih.gov/pmc/articles/PMC7473149/pdf/main.pdf.

Rosa, M. E. E., Matos, M. J. R., Furtado, R. S. O. P., Brito, V. M., Amaral, L. T. W., Beraldo, G. L., Fonseca, E. K. U. N., Chate, R. C., Passos, R. B. D., Teles, G. B. S., Yokoo, P., Yanata, E., Shoji, H., Szarf, G. \& Funari, M. B. G. (2020). Achados da COVID-19 identificados na tomografia computadorizada de tórax: ensaio pictórico. Einstein, 18. https://www.scielo.br/j/eins/a/sP9DRDdfTWpR6ZvZkqXxHXx/?format=pdf\&lang=pt.

Sanchez-Oro, R.; Nuez, J. T. \& Martinez-Sanz, G. (2020). Radiologia no diagnóstico da pneumonia SARS-CoV-2 (COVID-19). Medicina Clínica, 155(1), 3640. https://www.sciencedirect.com/science/article/pii/S0025775320301858?via\%3Dihub.

Tenda, E. D., Yulianti, M., Asaf, M. M., Yunus, R. E., Septiyanti, W., Wulani, V., Pitoyo, C. W., Rumende, C. M. \& Setiati, S. (2020). A importância da tomografia computadorizada de tórax no COVID-19: uma série de casos. The Indonesian Journal of Internal Medicine, 52(1), 68-73. http://www.actamedindones.org/index.php/ijim/article/view/1430/pdf.

Wang, D., Hu, B., Hu, C., Zhu, F., Liu, X., Zhang, J., Wang, B., Xiang, H., Cheng, Z., Xiong, Y., Zhao, Y., Li, Y., Wang, X. \& Peng, Z. Características clínicas de 138 pacientes hospitalizados com pneumonia infectada por coronavírus 2019 em Wuhan, China. The Journal of the American Medical Association, 323(11), 1061-1069. https://jamanetwork.com/journals/jama/article-abstract/2761044.

Xie, X., Zhong, Z., Zhao, W., Zheng, C., Wang, F. \& Liu, J. (2020). TC de tórax para pneumonia nCoV 2019 típica: relação com teste de RT-PCR negativo. Radiology, 296(2), E41-E45. https://pubs.rsna.org/doi/10.1148/radiol.2020200343.

Xu, X., Yu, C., Qu, J., Zhang, L., Jiang, S., Huang, D., Chen, B., Zhang, Z., Guan, W., Ling, Z., Jiang, R., Hu, T., Ding, Y., Lin, L., Gan, Q., Luo, L., Tang, X. \& Liu, J. (2020). Imagem e características clínicas de pacientes com novo coronavírus SARS-CoV-2 2019. European Journal of Nuclear Medicine and Molecular Imaging, 47(1), 1275-1280. https://link.springer.com/article/10.1007/s00259-020-04735-9.

Ye, Z., Zhang, Y., Wang, Y., Huang, Z. \& Song, B. (2020). Manifestações de TC de tórax de nova doença coronavírus 2019

(COVID-19): uma revisão pictórica. European Radiology. https://www.ncbi.nlm.nih.gov/pmc/articles/PMC7088323/pdf/330_2020_Article_6801.pdf.

Zhu, N., Zhang, D. Wang, W., Li, X., Yang, B., Song, J., Zhao, X., Huang, B., Shi, W., Lu, R., Niu, P., Zhan, F., Ma, X., Wang, D., Xu, W., Wu, G., Gao, G. F. \& Tan, W. (2020). Um novo coronavírus de pacientes com pneumonia na China, 2019. New England Journal of Medicine, 382(8), 727-733. https://www.nejm.org/doi/full/10.1056/nejmoa2001017. 